\title{
Alzheimer disease health-related information on YouTube: A video reviewing study
}

\author{
Mohammad Abu Sabra , Andaleeb Abu Kamel, Malakeh Z. Malak \\ Faculty of Nursing, Al-Zaytoonah University of Jordan (ZUJ), Jordan
}

Received: May 8, 2016

DOI: $10.5430 /$ jnep.v6n10p116
Accepted: May 26, 2016

Online Published: June 14, 2016

\begin{abstract}
Background: Alzheimer disease is a common cause of cognitive impairment among elders. Until now, there is no absolute management to treat the disease. Raising awareness of population regarding Alzheimer disease and its management is a top priority goal for different health organizations.

Methods: Recently, using different mass media, specifically YouTube to share Alzheimer health-related information become increasingly apparent. The purpose of this study was to review the content of YouTube videos regarding Alzheimer disease health-related information. The searching key terms of Alzheimer disease, and education, management, and care were used. Videos were critically analyzed for content, method of presentation, and caregivers.

Results: A total of 1,050 videos were reviewed, 513 videos were excluded because of misleading and duplication. Five hundred and thirty seven videos were analyzed. The most common type of videos classification was education. The majority of video content reviewed was signs and symptoms of Alzheimer disease. Slide presentation was the main method of presenting information (28.7\%). The highest number caregivers in the videos review was for physician (32.4\%). The total views of the videos were 4,831,853 views, 32,733 likes, and 1,060 dislikes.

Conclusion: YouTube videos of Alzheimer disease were frequently viewed. However, inaccurate or incomplete health-related information was noticeable. Community of caregivers has a clear opportunity to enhance the value and quality of educational material on YouTube. Moreover, the nurses should have a significant role in uploading accurate health-related information regarding Alzheimer disease YouTube videos.
\end{abstract}

Key Words: Alzheimer disease, Caregiver, Education, Management, YouTube

\section{INTRODUCTION}

\subsection{Alzheimer disease}

Alzheimer's disease (AD) is the most common cause of dementia and may contribute to $60 \%-70 \%$ of cases. Dementia is a syndrome, which is manifested by deterioration in memory, thinking, the ability to perform Activities of Daily Living (ADL), and behaviors. ${ }^{[1]}$ Alzheimer's disease is a progressively serious and ultimately fatal disorder. ${ }^{[2]}$ During 2015, the global prevalence of $\mathrm{AD}$ has been estimated to be 48 million people. ${ }^{[3]}$ In a vital statistical report, during 2013 the mortality rate of $\mathrm{AD}$ was 26.6 death, and it was ranked as the sixth cause of death in United State. ${ }^{[4]}$

The most common early symptoms of AD are difficulty remembering of recent learned information and impairment of judgment. Over time, symptoms may progress to confusion, forgetting family members, disorientation in familiar surroundings, problems with language, mood swings, loss

*Correspondence: Mohammad Abu Sabra; Email: m.sabra@zuj.edu.jo; Address: Faculty of Nursing, Al-Zaytoonah University of Jordan (ZUJ). PO box 130, Amman 11733, Jordan. 
of motivation, behavioral issues such as wandering, and selfcare deficit. ${ }^{[3,5]}$ Although the speed of progression can vary, the average life expectancy following diagnosis is three to nine years. ${ }^{[6]}$

The etiology of AD is varied and poorly understood. Many studies discussed the effect of genetics, environmental factors, familial/early onset, history of head injuries, depression, diabetes and hypertension on occurrence of AD. ${ }^{[7,8]}$ Aging represents the most important risk for developing $\mathrm{AD}$, the more individuals advance in age are the higher risk to develop the disease. The majority of patients develop AD at the age 65 years and beyond. ${ }^{[5]}$ The risk of developing AD reaches $50 \%$ for individuals older than age $85 .{ }^{[9]}$

There are no definite curable treatments for AD progression; some treatments may temporarily improve symptoms. ${ }^{[3]}$ Management of Alzheimer's disease could be divided into pharmaceutical, psychosocial and caregiving. ${ }^{[10]}$

Different types of medications are used to maintain thinking, memory, communication and help with certain behavioral problems. However, these medications do not treat or alter the disease process. ${ }^{[2]}$

Different approaches of psychosocial interventions were used to manage AD manifestations such as behavioral, emotional, cognition or stimulation-oriented method. ${ }^{[11]}$ There is an evidence for ineffectiveness of behavioral intervention in improving overall AD clients' functioning. ${ }^{[12]}$ Furthermore, behavioral intervention can reduce incontinence problem. ${ }^{[13]}$

Caregiving is essential in the treatment of AD and it is provided according to the stage of the disease. During the early and moderate stages, modifications of the patients' environment and lifestyle are required in order to increase patient safety and decrease caregiver strain. ${ }^{[14,15]}$ During the final stages of the disease, treatment is focused on providing comfort until death through palliative care, often with the help of hospice. ${ }^{[16]}$ People with AD increasingly rely on informal caregivers such as family members, friends, relatives or neighbors for ADL assistance. ${ }^{[17]}$

Caring for a family member with AD is stressful and burdensome and often placing a burden on the caregiver, which include social, psychological, physical, and economic aspects. ${ }^{[18]}$ The people with $\mathrm{AD}$ and their families prefer home care. ${ }^{[19]}$ Home care delays or reduces the need for more professional and costly levels of care. ${ }^{[19,20]}$ All persons who are engaged in long-term caring for AD clients need to be prepared through all available channels to be effective caregivers. The most popular and contemporary available channel for obtaining health-related information is the social media, specifically YouTube.

\subsection{YouTube as source for health-related information}

People turn to internet for seeking advices as a complementary source of health-related information. ${ }^{[21]}$ The characteristic of this source is the speed of retrieving information with low cost property. YouTube is the world's leader video sharing site. It is the third most visited website and is the key provider of health-related information. ${ }^{[22]}$

YouTube is a free service in which the users can upload videos through the internet, via websites, mobile devices, blogs or e-mails then sharing them with hundred million viewers. ${ }^{[23]}$ It was used frequently in medical, health, and nursing formal teaching-learning process for students. ${ }^{[24,25]}$ Additionally, YouTube was used as a mean to present different health-related information for lay people such as cancer, ${ }^{[26,27]}$ kidney stones, ${ }^{[28]}$ epilepsy, ${ }^{[29]}$ and other public health issues such as obesity, ${ }^{[30]}$ and quitting smoking. ${ }^{[31]}$

Up to date and based on a thorough searching of available literature, there is a lack of studies aimed at exploring AD health-related information on social media in Arab countries. The key aim of this review was to analyze the content of AD information on YouTube to assess the contents in term quality, accuracy of information, credibility of the source of information. It is important for nurses to gain insight on the available AD health-related and information on YouTube as a most popular channel of health retrieving information.

\section{METHOD}

The video review method was developed and drawn upon a previous method for analyzing YouTube video content. ${ }^{[32]} \mathrm{A}$ review of YouTube videos was conducted between December 2015 and March 2016. Researchers used the following key terms; Alzheimer disease, and education, management, and caregiver in English language. For more inclusive search, researchers used Arabic words of the above key terms. Researchers developed data sheet to screen each video for the following criteria: language, content of the video, caregiver appearance, and method of information presentation. Accuracy of the video content was evaluated against the content of a well credible AD related institution. ${ }^{[5]}$

Videos were excluded if they were duplicated, not related to study theme or misleading.

To minimize duplication of the yielded data, one researcher was assigned to review the video and to fill data sheet. Furthermore, to avoid subjectivity, another researcher reviewed the same videos and filled data sheets and then both sheets were compared to assure well-matched information. Data analysis was conducted by using SPSS software 22, and descriptive statistics were calculated. 


\section{RESUlts}

A total of 1,050 YouTube videos were reviewed. Of this number, $537(51.1 \%)$ videos were met the inclusion criteria. A number of 513 videos were excluded from analysis because of different causes such as; duplication of the same video, the content was not related to the study theme and misleading causes. Only $14.3 \%$ of the videos were presented in Arabic language (see Figure 1). The total views of the videos were 4,831,853 views, 32,733 likes, and 1,060 dislikes.

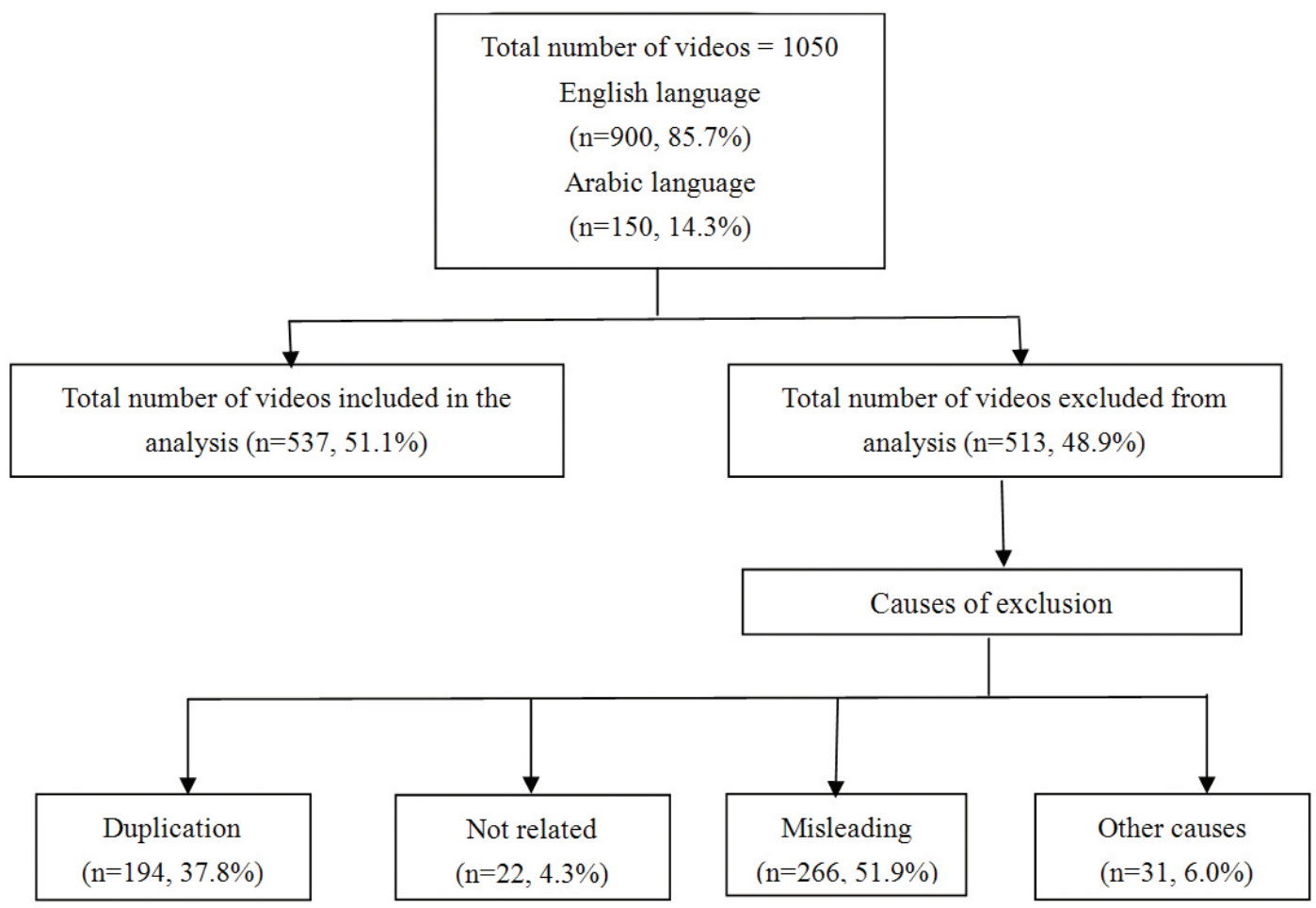

Figure 1. The number of the videos and the exclusion process

The classification categories of the source of the videos were mainly education $(35.8 \%)$, people and blogs $(22.3 \%)$, nonprofit and activism (12.8\%), science and technology (11.0\%), then other sources $(18.1 \%)$. Concerning the method of presenting information, the results revealed that more than onequarter of the videos presentation was for slide presentation $(28.7 \%)$. On the contrary, $2.6 \%$ of the videos used simulation and demonstration (see Table 1).

Table 1. Methods of presenting Alzheimer disease health-related information

\begin{tabular}{lll}
\hline Presentation methods & $\mathbf{n}$ & $\mathbf{\%}$ \\
\hline Slide presentation & 154 & 28.7 \\
Multiple & 123 & 22.9 \\
Interview & 99 & 18.4 \\
Speech only & 48 & 8.9 \\
Role Play & 43 & 8.0 \\
Simulation and demonstration & 14 & 2.6 \\
Other types of presentations & 56 & 10.4 \\
\hline Total & $\mathbf{5 3 7}$ & $\mathbf{1 0 0}$ \\
\hline
\end{tabular}

As shown in Table 2 regarding the analysis of the videos content, the results indicated that the majority of the videos discussed the signs and symptoms of the disease $(60.1 \%)$, while $14.2 \%$ presented physiology of the disease (see Table 2).

Table 2. Content of the videos

\begin{tabular}{lll}
\hline Content of the videos & $\mathbf{n}$ & $\mathbf{\%}$ \\
\hline Sign and symptoms of the disease & 326 & 60.1 \\
Family support & 270 & 50.3 \\
Treatment plan & 268 & 49.9 \\
Definition of the disease & 253 & 47.1 \\
Family education and training & 152 & 28.3 \\
Progress of the disease & 137 & 25.5 \\
Physiology of the disease & 76 & 14.2 \\
\hline
\end{tabular}

Note. The numbers and percentages are not mutually exclusive

The results indicated that $63.9 \%$ of the videos had no personal appearance (slide show), $30.5 \%$ presented real persons, and $5.6 \%$ were simulations. The results showed that the majority of clinician in videos were physicians and informal caregivers $(32.4 \%)$ and $(23.2 \%)$ respectively, while $2.6 \%$ were nurses (see Table 3 ). 
Table 3. Number of caregivers in YouTube videos

\begin{tabular}{|c|c|c|c|}
\hline & & Caregivers & n (\%) \\
\hline \multirow{6}{*}{$\begin{array}{l}\text { Caregivers } \\
\text { in the } \\
\text { reviewed } \\
\text { videos }\end{array}$} & \multirow{5}{*}{$\begin{array}{l}\text { Formal } \\
\text { caregivers }\end{array}$} & Physician & $174(32.4 \%)$ \\
\hline & & $\begin{array}{l}\text { Other health personnel } \\
\text { (pharmacist, } \\
\text { physiotherapist, dietitian) }\end{array}$ & 88 (16.4\%) \\
\hline & & Nurses & $14(2.6 \%)$ \\
\hline & & Health team & 27 (5.0\%) \\
\hline & & Not identified & 61 (11.4\%) \\
\hline & $\begin{array}{l}\text { Informal } \\
\text { caregivers }\end{array}$ & $\begin{array}{l}\text { Family members, friends, } \\
\text { neighbor }\end{array}$ & 147 (32.2\%) \\
\hline
\end{tabular}

Note. The numbers and percentages are not mutually exclusive.

\section{Discussion}

This review study revealed that the AD health-related information is available and vast in content perspectives. The findings showed that $51.9 \%$ of the excluded reviewed videos had misleading information, which is higher than the rate reported in previous studies. ${ }^{[32,33]}$ A previous study found that searching terms and the declared disseminator source were principal requirements for accessing quality health-related videos. ${ }^{[34]}$ This issue highlights the importance of publishing health information via official, or Alzheimer specialized organizations with definite and fixed searching terms to enable audience to access their quest easily. This review of YouTube videos implies that a considerable number of videos presented inaccurate or insufficiency in certain content about the disease. AD health care providers should be aware of this issue and direct their patients and caregivers to refer to definite sources of evidence-based health-related videos. Furthermore, the disseminator of the videos should be official and professional Alzheimer specialized personnel and organizations. ${ }^{[33]}$

This study revealed that the most common type of videos classification was education. YouTube supports the delivery of education that is immediate, active rather than passive, and facilitating a rapid low-cost sharing of experiences and opinions. ${ }^{[35]}$ Education through YouTube provides an opportunity for experts and professional in knowledge field to share insights with a specific community or the public at large, bypassing formal structures of information dissemination. ${ }^{[35]}$ This study revealed that more than quarter of the videos used slide presentation, which could be attributed to the affordable cost of this way of presentation. Presenting AD information through demonstration was rarely used in this study, which is congruent with a previous study. ${ }^{[35]}$ Demonstration could be problematic because it requires expensive resources and extensive preparation.

The quality and credibility of the presented content were varied depending on the disseminating source; however this issue cannot be ignored since a previous study considered
YouTube as source of poor and fair or even not reliable health information for prostate cancer. ${ }^{[27]}$ The issue of credibility and trustworthy issues of YouTube videos forced Kreslen et al. to recommend a novel method of re-ranking health related YouTube videos according to certain domains and according to source of the video uploader. ${ }^{[36]}$

The findings of this study indicated that the most common content of AD videos was signs and symptoms. On the contrary, the $\mathrm{AD}$ informal caregiver education on YouTube is generally lacking. This result should encourage the community health care providers to develop and upload videos regarding this content.

Lacking of attention of Arab population to the importance $\mathrm{AD}$ could be the cause behind the low number of AD video in Arabic language. Health care providers could have the benefit of the contemporary and accessibility of YouTube site to disseminate health-related information in Arabic language.

It is significant here to highlight the importance of presenting information through appropriate caregiver. The findings of the current study indicate that the highest percentage featuring of caregivers in the reviewed videos was physicians. Consistent with a previous study, health care providers were the major caregivers. ${ }^{[32]}$ However, an increase number of videos by physician do not necessarily ensure quality of the provided content. MacLeod et al., ${ }^{[37]}$ found that the quality of YouTube videos was poor, even though these videos generated by health care professionals. Therefore, formal caregivers especially physicians and nurses should be alert about the quality of video content when uploading AD healthrelated information to YouTube sites. Moreover, there was low number of videos for nurses as formal caregivers. This result supports the needs for health-related information videos uploaded by nurses, focusing on the nursing scope of familycentered care and nursing roles as family educator and family caregiver.

The results showed that the number of views were high in comparison with number of likes and dislikes. This could be explained by that; YouTube users are required to register and subscribe to be eligible to use YouTube options of comments, like or dislike, so most people were not registered as YouTube users. ${ }^{[32]}$

\subsection{Strength and limitations}

The strength of this study was the ability of researchers to capture 1,050, videos which is considered as larger than any number of videos investigated in previous studies which restricted maximally to 500 videos. This study shed a light on the availability of instructional AD videos as health-related information resource. It was not possible to include an un- 
limited number of YouTube Alzheimer health-related information because of the misleading issues and the searching process was limited to specific terms. Another limitation of this study was the endless changing of the number of the uploaded videos on YouTube, and this study was specifically conducted within a limited time.

\subsection{Conclusion}

YouTube is a widely popular video sharing site. Therefore, it should be used to disseminate high quality and credible information regarding AD for global audiences. This study showed that YouTube has a large number of videos on $\mathrm{AD}$ with content focusing on signs and symptoms. YouTube, despite its huge potential as health information dissemination platform, cannot be deemed as a good source of accurate and complete information. Considering the growing popularity and easy accessibility of YouTube, different organizations should contribute in making genuine videos on $\mathrm{AD}$ education about caregiving, management, and treatment specifically for Arab community.

Future studies can compare the quality of AD health-related information between the official and non-official organizations. Researchers highly recommend further studies on how YouTube lay people consumers absorb the AD related information and to what extent the information was beneficial for them.

\section{CONFlicts OF INTEREST Disclosure}

The authors have no potential conflicts of interest.

\section{REFERENCES}

[1] World Health Organization. Dementia: Factsheet. 2016. Available from: http://www.who.int/mediacentre/factsheets /fs362/en/

[2] National Institute of Aging. About Alzheimer's disease: Treatment. 2016. Available from: https://www.nia.nih.gov/alzheimers /topics/treatment

[3] World Health Organization. Dementia: Fact sheet. 2015. Available from: http://www.who.int/mediacentre/factsheets /fs362/en/

[4] Centers for Disease Control and Prevention. Deaths: Final Data for 2013. 2013. Available from: http://www.cdc.gov/nchs/data/ nvsr/nvsr64/nvsr64_02.pdf

[5] Alzheimer Association. What is Alzheimer's? 2016. Available from: http://www.alz.org/alzheimers_disease_what_is _alzheimers.asp

[6] Todd S, Barr S, Roberts M, et al. Survival in dementia and predictors of mortality: a review. International Journal of Geriatric Psychiatry. 2013; 28(11): 110924. PMid: 23526458. http://dx.Doi.org/10. 1002/gps. 3946

[7] Burns A, Iliffe S. Alzheimer's disease. BMJ. 2009; 338: 46471. http://dx.doi.org/10.1136/bmj.b158

[8] Mayeux R, Stern Y. Epidemiology of Alzheimer Disease. Cold Spring Harbor Perspectives in Medicine. 2012; 2. http://dx.doi.org/1 $0.1101 /$ cshperspect.a006239

[9] Ziegler-Graham. Alzheimer \& Dementia. 2008; 4: 316-328.

[10] National Institute of Neurological Disorders and Stroke. NINDS Alzheimer's disease information page. US National Institutes of Health. 2013. Available from: http://www.ninds.nih.gov/

[11] Rabins PV, Blacker D, Rovner BW, et al. American Psychiatric Association practice guideline for the treatment of patients with Alzheimer's disease and other dementias. The American Journal of Psychiatry. 2007; 164(12 Suppl): 5-56. PMid:18340692.

[12] Bottino CM, Carvalho IA, Alvarez AM, et al. Cognitive rehabilitation combined with drug treatment in Alzheimer's disease patients: a pilot study. Clinical Rehabilitation. 2005; 19(8): 861-869. PMid:16323385. http://dx.Doi.org/10.1191/0269215505cr911oa

[13] Doody RS, Stevens JC, Beck C, et al. Practice parameter: management of Dementia (an evidence-based review). Report of the Quality Standards Subcommittee of the American Academy of
Neurology. Neurology. 2001; 56(9): 1154-1166. PMid: 11342679. http://dx.Doi.org/10.1212/WNL.56.9.1154

[14] Gitlin LN, Corcoran M, Winter L, et al. A randomized Controlled Trial of a Home Environmental Intervention: Effect on Efficacy and Upset in Caregivers and on Daily Function of Persons with Dementia. The Gerontologist. 2001; 41(1): 4-14. PMid: 11220813. http://dx.doi.org/10.1093/geront/41.1.4

[15] Gitlin LN, Hauck WW, Dennis MP, et al. Maintenance of Effects of The Home Environmental Skill-building Program for Family Caregivers and Individuals with Alzheimer's Disease and Related Disorders. The Journals of Gerontology. Series A, Biological Sciences and Medical Sciences. 2005; 60(3): 36874. PMid:15860476. http://dx.doi.org/10.1093/gerona/60.3.368

[16] Shega JW, Levin A, Hougham GW, et al. Palliative Excellence in Alzheimer Care Efforts (PEACE): A Program Description. Journal of Palliative Medicine. 2003; 6(2): 315-20. PMid:12854952. http://dx.doi.org/10.1089/109662103764978641

[17] Family Caregiver Alliance. National Center on Caregiving. 2016. Available from: https://www. caregiver.org/national-cen ter-caregiving

[18] National institute on aging. Alzheimer's disease: Factsheet. 2016. Available from: https://www.nia.nih.gov/alzheimers/pub lication/alzheimers-disease-fact-sheet

[19] Zhu CW, Sano M. Economic Considerations in the Management of Alzheimer's disease. Clinical Interventions in Aging. 2006; 1(2): 14354. PMid:18044111. http://dx.doi.org/10.2147/c iia.2006.1.2.143

[20] Gaugler JE, Kane RL, Kane RA, et al. Early Community- Utilization and Its Effects on Institutionalization in Dementia Caregiving. The Gerontologist. 2005; 45(2): 17785. PMid:15799982. http://dx.doi.org/10.1093/geront/45.2.177

[21] Van de Belt TH, Engelen LJ, Berben SA, et al. Internet and social media for health-related information and communication in health care: preferences of the Dutch general population. Journal of Medical Internet Research. 2013; 15(10): e220. PMid:24088272. http://dx.doi.org/10.2196/jmir. 2607

[22] Vance K, Howe W, Dellavalle RP. Social internet sites as a source of public health information. Dermatol Clin. 2009; 27: 133136. PMid:19254656. http://dx.doi.org/10.1016/j.det.2 008.11 .010 
[23] Artero JP. Online video business models: YouTube vs. Hulu. Palavra Clave. 2010; 13: 111-123.

[24] Clifton A, Mann C. Can YouTube enhance student nurse learning? Nurse Education Today. 2011; 31(4): 311-313. PMid:21036430. http://dx.doi.org/10.1016/j.nedt.2010.10.004

[25] Jaffar AA. YouTube: an emerging tool in anatomy education. Anatomical Sciences Education. 2012; 5(3): 158-164. PMid:22383096. http://dx.doi.org/10.1002/ase.1268

[26] Chou WY, Hunt Y, Folkers A, et al. Cancer survivorship in the age of YouTube and social media: a narrative analysis. Journal of Medical Internet Research. 2011; 13(1): e7. PMid: 21247864. http://dx.doi.org/10.2196/jmir.1569

[27] Steinburg PL, WEason S, Stern J, et al. YouTube as a source of prostate cancer information. Urology. 2010; 75(3): 619-622. PMid:19815255. http://dx.doi.org/10.1016/j.urology.2 008.07 .059

[28] Sood A, Sarangi S, Pandey A, et al. YouTube as a source of information on kidney stone disease. Urology. 2011; 77 (3): 55862. PMid:21131027. http://dx.doi.org/10.1016/j.urology .2010 .07 .536

[29] Lo AS, Esser MJ, Gordon KE. YouTube: a gauge of public perception and awareness surrounding epilepsy. Epilepsy \& Behavior. 2010; 17(4): 541-5. PMid:20236867. http://dx.doi.org/10.1016/j .yebeh.2010.02.004

[30] Yoo JH, Kim J. Obesity in the new media: a content analysis of obesity videos on YouTube. Health Communication. 2012; 27(1): 8697. PMid:21809934. http://dx.doi.org/10.1080/10410236. 2011.569003
[31] Backinger CL, Pilsner AM, Augustson EM, et al. YouTube as a source of quitting smoking information. Tobacco Control. 2011; 20(2): 119-122. PMid:20966132. http://dx. doi .org/10.1136 /tc. 2009.035550

[32] Gonzalez-Estrada A, Cuervo-pardo L, Ghosh B, et al. Popular on YouTube: A critical appraisal of the education quality of information regarding asthma. 2015; 36(6): e121-6. PMid:26534743. http://dx.doi.org/10.2500/aap.2015.36.3890

[33] Singh A, Singh S, Singh P. YouTube for information on rheumatoid arthritis-A wakeup call? J Rheumatol. 2012; 39(5): 899-903. PMid:22467934. http://dx.doi.org/10.3899/jrheum.1111 14

[34] Fat M, Doja A, Barrowman N, et al. YouTube videos as a teaching tool for patient resource for infantile spasms. J Child Neurol. 2011; 26(7): 804-809. PMid:21551373. http://dx.doi.org/10.1177 10883073811402345

[35] Wittenberg-Lyles E, Oliver D, Demiris G, et al. YouTube as a Tool for Pain Management With Informal Caregivers of Cancer Patients: A Systematic Review. Journal of Pain and Symptom Management. 2014; 48(6).

[36] Karlsen R, Borras Morell JE, Fernandes luque L, et al. A DomainBased Approach for Retrieving Trustworthy Health Videos from YouTube. 2013; 192: 1008. PMid:23920782. http://dx.doi.org /10.3233/978-1-61499-289-9-1008

[37] MacLeod MG, Hoppe DJ, Simunovic N, et al. YouTube as an information source for femoroacetabular impingement: A systematic review of video content. Arthroscopy. 2015; 31: 136-142. PMid:25150406. http://dx.doi.org/10.1016/j.arthro.2014.06.009 